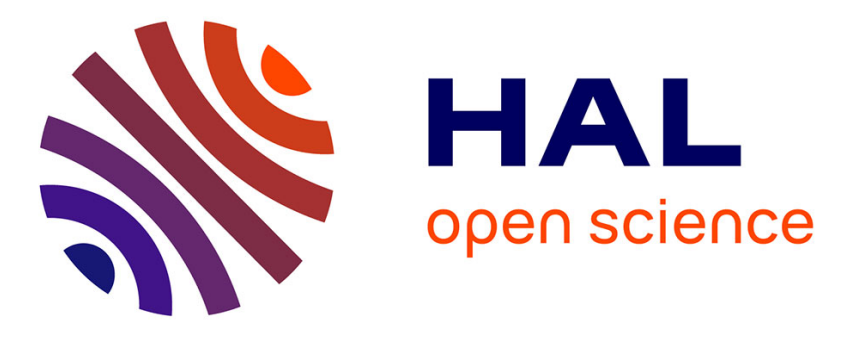

\title{
Hit optimization studies of 3-hydroxy-indolin-2-one analogs as potential anti-HIV-1 agents
}

Subhash Chander, Cheng-Run Tang, Ashok Penta, Ping Wang, Deepak P Bhagwat, Nicolas Vanthuyne, Muriel Albalat, Payal Patel, Sanskruti Sankpal, Yong-Tang Zheng, et al.

\section{To cite this version:}

Subhash Chander, Cheng-Run Tang, Ashok Penta, Ping Wang, Deepak P Bhagwat, et al.. Hit optimization studies of 3-hydroxy-indolin-2-one analogs as potential anti-HIV-1 agents. Bioorganic Chemistry, 2018, 79, pp.212-222. 10.1016/j.bioorg.2018.04.027 . hal-02092303

\section{HAL Id: hal-02092303 https://hal.science/hal-02092303}

Submitted on 8 Apr 2019

HAL is a multi-disciplinary open access archive for the deposit and dissemination of scientific research documents, whether they are published or not. The documents may come from teaching and research institutions in France or abroad, or from public or private research centers.
L'archive ouverte pluridisciplinaire HAL, est destinée au dépôt et à la diffusion de documents scientifiques de niveau recherche, publiés ou non, émanant des établissements d'enseignement et de recherche français ou étrangers, des laboratoires publics ou privés. 


\section{Hit optimization studies of 3-hydroxy-indolin-2-one analogs as potential anti-HIV-1 agents}

Subhash Chander ${ }^{\mathrm{a}, \mathrm{c}, 1}$, Cheng-Run Tang ${ }^{\mathrm{b}, \mathrm{d}, 1}$, Ashok Penta ${ }^{\mathrm{a}}$, Ping Wang ${ }^{\mathrm{b}, \mathrm{d}}$, Deepak P. Bhagwat ${ }^{\mathrm{c}}$, Nicolas Vanthuyne ${ }^{\mathrm{e}}$, Muriel Albalat ${ }^{\mathrm{e}}$, Payal Patel ${ }^{\mathrm{a}}$, Sanskruti Sankpal ${ }^{\mathrm{a}}$, Yong-Tang Zheng ${ }^{\mathrm{b}, *}$, Murugesan Sankaranarayanan ${ }^{\mathrm{a}, *}$

${ }^{a}$ Medicinal Chemistry Research Laboratory, Department of Pharmacy, Birla Institute of Technology \& Science, Pilani Campus, Pilani 333031, Rajasthan, India

${ }^{\mathrm{b}}$ Key Laboratory of Bioactive Peptides of Yunnan Province/Key Laboratory of Animal Models and Human Disease Mechanisms of Chinese Academy of Sciences, Kunming Institute of Zoology, Chinese Academy of Sciences, Kunming, Yunnan 650223, China

School of Pharmacy, Maharaja Agrasen Universily, Atal Shisha Kunj, Village Kalujhanda, Solan, Himachal Pradesh 174103, India

for Natural Products, Kunming Medical University, Kunming, Yunnan 650500, China

Aix-Marseille Univ, CNRS, Centrale Marseille, iSm2, Marseille, France

\section{A B S T R A C T}

In the current study, twenty-two compounds based upon 3-hydroxy-3-(2-oxo-2-phenylethyl)indolin-2-one nucleus were designed, synthesized and in vitro evaluated for HIV-1 RT inhibition and anti-HIV-1 activity Compounds 3d, 5c and 5e demonstrated encouraging potency against RT enzyme as well as HIV-1 in low micromolar to nanomolar concentration with good to excellent safety index. Structure activity relationship studies revealed that halogens such as bromo or chloro at 5th the position of oxindole ring remarkably enhanced the potency against RT. Moreover, methoxy or chloro groups at the ortho position of phenyl ring also significantly favored RT inhibition activity. Seven compounds ( $3 b, 3 c, 3 d, 3 e, 5 b, 5 c$ and 5 e) with better anti-HIV(a) 1 potency were tested against the mutant $\mathrm{HIV}-1_{\mathrm{K} 103 \mathrm{~N}}$ strain. The putative binding mode, as well as interaction
patterns of the best active compound $5 \mathbf{c}$ with wild HIV-1 RT were studied via docking studies.

\section{Introduction}

Non-Nucleoside Reverse Transcriptase Inhibitors (NNRTIs) act at allosteric site of HIV-1 RT in a non-competitive manner and inhibits its catalytic activity. Subsequently, inhibition of catalytic activity hampers the synthesis of double-stranded DNA copy of the viral genome [1,2]. Central role of RT enzyme in the life cycle of HIV makes it an attractive target and it has been exploited clinically for reduction of viral load from serum [3]. NNRTIs are crucial component of the current anti-HIV therapy named Highly Active Anti Retroviral Therapy (HAART), due to their potent anti-viral activity, high specificity and low toxicity [4-6]. However, continuous emergence of drug resistance against clinically used NNRTIs compromises their usefulness [7]. Resistance generally arises due to single point or multiple mutations at the Non-Nucleoside Inhibitory Binding Pocket (NNIBP) [8,9]. Among the patients receiving NNRTIs therapy, mutations like K103N and K103N/Y181C in HIV-1 RT are more frequently observed inside the NNIBP. In general, single mutation in NNIBP like $\mathrm{K} 103 \mathrm{~N}$ is adequate in reduction of RT sensitivity towards the first line drugs, while dual mutant strains (K103N/Y181C) exhibit totally resistant against the first generation NNRTIs and also reduced the efficacy of second generation NNRTIs $[10,11]$. Overall, ever emerging problem of drug resistance against the clinically available anti-HIV-1 drugs drive the need for search of new drugs having improved efficacy against wild as well as mutant RT strains with favourable pharmacokinetic profile.

Target based virtual screening techniques has made drug discovery process fast, more economic and goal-oriented, such techniques have been recognized as crucial tool in drug discovery and development process [12-14]. Moreover, similar strategy has also been utilized for the discovery of potential anti-HIV-1 agents [15-17]. In our previous study, attempts were made for the search of NNRTIs using structurebased virtual screening against wild and two mutant strains K103N and K103N/Y181C. Finally, nine hits were shortlisted in the study which exhibited significant in silico activity against three selected strains [18]. In another recently published report as an extension of the above mentioned virtual studies, we synthesized and evaluated compounds 


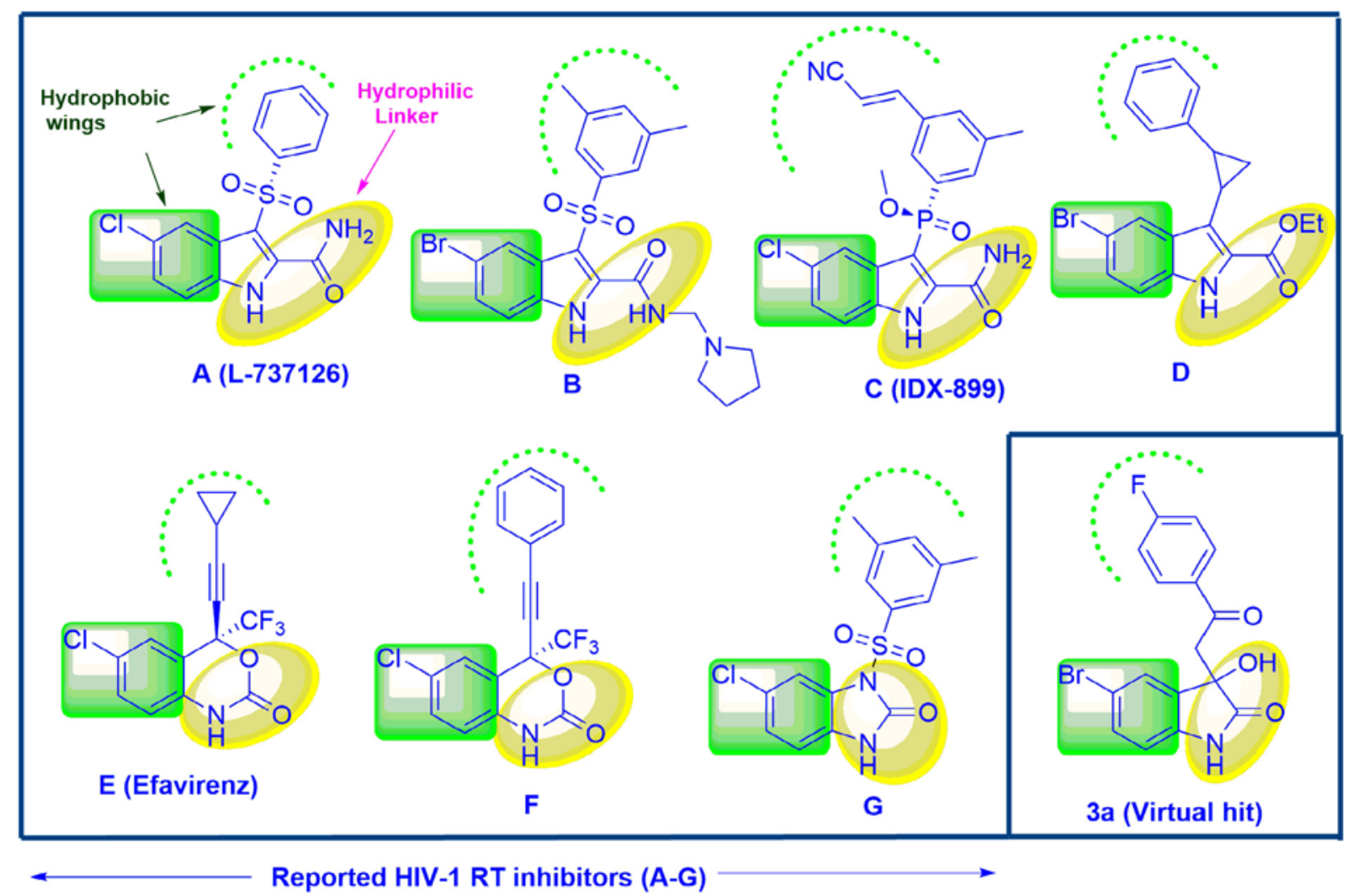

Fig. 1. Literature reported potential HIV-1 RT inhibitors (A-G) and virtual screening hit (3a).

based on benzodiazepin-2-one nucleus against wild RT, the overall study afforded two hits against wild RT with low micro molar potency $(>10 \mu \mathrm{M})$ and good safety index $(>46)$. The finding of the above study provokes our interest to explore more virtual screened hits for anti-HIV-1 activity [19].

Despite the structural diversity of NNRTIs, they share common set of pharmacophoric features, which consist of phenyl ring at one terminal and an aromatic or hydrophobic wing at the second terminal, while at the centre NNRTIs possess a hydrophilic linker like amide, thioamide or glycinamide [20,21]. Phenyl or hydrophobic part of NNRTIs form hydrophobic interactions with the non-polar residues like Phe-227, Tyr181, Tyr-188, Trp-229 and Leu-234 of NNIBP, while central polar linker interacts with the hydrophilic residues like Lys-101 and Lys-103 via hydrogen bonding interactions $[22,23]$.

In the current study, we selected one more hit based on 3-hydroxy3-(2-oxo-2-phenylethyl)indolin-2-one (3a, Fig. 1) from the virtual screening studies [18] and decided to proceed for synthesis, RT inhibition and anti-HIV-1 evaluation studies. Through literature study revealed that compounds containing the similar pharmacophoric features are already reported as potential inhibitors of HIV-1 RT. In a similar study, Williams and co-workers reported potential anti-HIV-1 RT and anti-HIV activity of compound 5-Chloro-3-(phenylsulfonyl)indole2-carboxamide (A) with $\mathrm{IC}_{50}$ and $\mathrm{EC}_{95}$ of $3 \mathrm{nM}$ [24]. In another report, La Regina et al., synthesized and evaluated series of compounds in which compound B showed potent activity against HIV-1 RT and HIV-1 with $\mathrm{IC}_{50}$ of $1.3 \mathrm{nM}$ and $\mathrm{EC}_{50}$ of $8 \mathrm{nM}$, respectively [25]. Dousson and team performed lead optimization studies of Aryl-Phospho-Indole as HIV-1 NNRTIs, afforded compound C (IDX899) as potent inhibitor with IC $_{50} 0.34 \mu \mathrm{M}[26,27]$. In another study, cyclopropyl-Indole based compounds were designed and evaluated for HIV-1 RT activity, among the series of compounds, D showed potent RT inhibitory potential with $\mathrm{IC}_{50} 0.066 \mu \mathrm{M}$ [28]. Efavirenz (E), a clinically approved NNRTIs and its structural analogue F possessed anti-HIV-1 and RT inhibition activity in low nano molar concentration, both drugs bear benzoxazin-2-one nucleus which shares pharmacophoric similarity with indole-2-carboxamide [29]. Another compound G based on benzoimidazol-2-one with similar functionality was also found to be potent inhibitor of HIV-1 RT and HIV-1 with IC $_{50} 5$ and $\mathrm{EC}_{50} 2 \mathrm{nM}$, respectively [30].

Anti-HIV potential of the above reported compounds having similar pharmacophoric features with the virtual screened hit (3a), encourage us to explore its RT inhibition potential. Next, in order to explore structure activity relationships (SARs), halogens like bromo, chloro and without substitution $(\mathrm{H})$ were tried at 5 th position of oxindole ring, while other hydrophobic wing (phenyl) was tried with different electron donating and withdrawing substituents (Scheme 1).

\section{Results and discussion}

\subsection{Chemistry}

To synthesize the target hit (3a), 5-bromoisatin and 4-fluoro acetophenone were used as starting materials; different reaction conditions (Table 1) were tried in order to standardize the reaction (Scheme 1). Frist, DMF and potassium carbonate were used as solvent and base respectively, after $4 \mathrm{~h}$ of stirring at room temperature, reaction mixture showed multiple spots on TLC. Next, acetonitrile and triethylamine were used, after heating the reaction mass at $80^{\circ} \mathrm{C}$ for $3 \mathrm{~h}$, multiple spots were again observed on TLC, including some unreacted starting material 5-chloroisatin. The spot having highest intensity on TLC was purified using column chromatography and characterized using various spectral techniques, which afforded $30 \%$ as desired product. Next, to enhance the yield, solvent and base was replaced with ethanol and diethyl amine, respectively and reaction mixture was stirred at room temperature. After six hours, reaction ended-up as single spot and desired compound 3a was obtained in $88 \%$ yield [31-35]. Rest of the compounds $\mathbf{3 b} \mathbf{b} \mathbf{5}$ jere synthesized in good to excellent yield (78-96\%) using the optimized reaction conditions of compound a3. All the synthesized compounds were characterized by spectral techniques like ${ }^{1} \mathrm{H}$ 
<smiles>[R7]c1ccc2c(c1)C(=O)C(=O)N2</smiles><smiles>[13CH3]</smiles><smiles>[R]c1ccc(C(C)=O)cc1</smiles>

2a-k $\mathbf{R}_{\mathbf{1}}=\mathrm{Br}, \mathrm{H}, \mathrm{Cl}$
$\mathbf{R}_{\mathbf{2}}=\mathrm{F}, \mathrm{H}, 3 \mathrm{Me}, 2 \mathrm{MeO}$

$3 \mathrm{MeO}, 4 \mathrm{~F}, 2 \mathrm{Cl}, 3 \mathrm{Cl}$

$3 \mathrm{Br}, 3 \mathrm{NO}_{2}, 3,4 \mathrm{Di}-\mathrm{MeO}$

$3,4-\mathrm{Di}-\mathrm{Cl}$<smiles>[R2]c1ccc(C(=O)CC2(O)C(=O)Nc3ccc([R])cc32)cc1</smiles>

3a: $R_{1}=B r, R_{2}=F$
3c: $R_{1}=B r, R_{2}=3 M e$
3e: $R_{1}=B r, R_{2}=2 C l$
4a: $R_{1}=H, R_{2}=F$
4c: $R_{1}=H, R_{2}=3 M e$
4e: $R_{1}=H, R_{2}=C l$
5a: $R_{1}=C l, R_{2}=F$
5c: $R_{1}=C l, R_{2}=2 M e O$
5e: $R_{1}=C l, R_{2}=2 C l$
5g: $R_{1}=C l, R_{2}=3 B r$
5i: $R_{1}=C l, R_{2}=3,4-D i-M e O$

3b: $\mathrm{R}_{1}=\mathrm{Br}, \mathrm{R}_{2}=\mathrm{H}$;

3d: $\mathrm{R}_{1}=\mathrm{Br}, \mathrm{R}_{2}=2 \mathrm{MeO}$;

3f: $R_{1}=B r, R_{2}=3 B r$

4b: $\mathrm{R}_{1}=\mathrm{H}, \mathrm{R}_{2}=\mathrm{H}$

4d: $R_{1}=H, R_{2}=2 M e O$

4f: $R_{1}=H, R_{2}=3 B r$

5b: $\mathrm{R}_{1}=\mathrm{Cl}, \mathrm{R}_{2}=\mathrm{H}$

5d: $\mathrm{R}_{1}=\mathrm{Cl}, \mathrm{R}_{2}=3 \mathrm{MeO}$

5f: $\mathrm{R}_{1}=\mathrm{Cl}, \mathrm{R}_{2}=3 \mathrm{Cl}$

5h: $\mathrm{R}_{1}=\mathrm{Cl}, \mathrm{R}_{2}=3 \mathrm{NO}_{2}$

5j: $\mathrm{R}_{1}=\mathrm{Cl}, \mathrm{R}_{2}=3,4-\mathrm{Di}-\mathrm{Cl}$

Scheme 1. Synthetic route for the titled compounds $(\mathbf{3} \mathbf{a}-\mathbf{5 j})$.

Table 1

Optimization of the reaction conditions to obtain hit compound 3a.

\begin{tabular}{lllll}
\hline S. No & Solvent & Base & $\begin{array}{l}\text { Reaction } \\
\text { condition }\end{array}$ & Inference \\
\hline a1 & $\mathrm{DMF}$ & $\mathrm{K}_{2} \mathrm{CO}_{3},(2 \mathrm{Eq})$. & $\begin{array}{l}\mathrm{rt}, 4 \mathrm{~h} \\
\text { heating, } 80^{\circ} \mathrm{C},\end{array}$ & $\begin{array}{l}\text { Multiple spots (not isolated) } \\
30 \% \text { yield (after column } \\
\text { purification) }\end{array}$ \\
$\mathrm{a} 2$ & $\mathrm{ACN}$ & $\mathrm{Et}_{3} \mathrm{~N},(2 \mathrm{Eq})$ & $3 \mathrm{~h}$ & $\begin{array}{l}88 \% \text { yield, single spot } \\
\text { reaction }\end{array}$ \\
$\mathrm{a} 3$ & $\mathrm{EtOH}$ & $\begin{array}{l}\mathrm{Et}_{2} \mathrm{NH}, \\
(1.2 \mathrm{Eq} .)\end{array}$ & $\mathrm{rt}, 6 \mathrm{~h}$ &
\end{tabular}

NMR, ${ }^{13} \mathrm{C}$ NMR, FTIR, ESI-MS and elemental analysis. Both enantiomers of the compound $\mathbf{5 c}$ were separated by using chiral preparative HPLC.

\subsection{Biological activity}

\subsubsection{In-vitro HIV-1 RT inhibition assay}

Initially, synthesized virtual hit (3a) was tested for wild HIV-1 RT inhibitory activity using RT assay kit (Roche). In the study, marketed drug efavirenz was used as a reference positive control while 5\% DMSO was taken as negative control [36,37]. Virtual hit compound 3a displayed moderate inhibitory potential against HIV-1 RT with IC $_{50}$ of $15.54 \mu \mathrm{M}$. In the next phase, keeping 5-bromo intact at oxindole system, compounds without substitution (3b) as well as different substitutions at phenyl ring (3c-f) were tested. Interestingly, compound without substitution at phenyl ring $3 \mathbf{b}$ showed better potency $(5.22 \mu \mathrm{M})$ than the virtual hit 3a. Further, electron donating methyl and methoxy groups at meta (3c) and ortho (3d) position enhanced the potency $\left(\mathrm{IC}_{50}=1.38\right.$ and $0.82 \mu \mathrm{M}$, respectively). Furthermore, halogen chloro group at ortho position (3e) also favored the inhibition potency $(2.03 \mu \mathrm{M})$, while bromo at meta position (3f) markedly decreased the RT inhibition potency (32.37 $\mu \mathrm{M})$. Further, to investigate the role of 5bromo at the oxindole ring on its RT inhibitory potential, compounds 4a-f were synthesized which possessed hydrogen instead of bromo and subsequently tested against HIV-1 RT. Unfortunately, replacement of bromo with hydrogen at oxindole was not found favorable for RT inhibition potency and except 4d, other compounds (4a, 4b, 4c, 4e and 4f) exhibited weak to least potency.

Next, compounds having 5-chloro at the oxindole ring and different substitution at the phenyl ring $(\mathbf{5 a} \mathbf{a} \mathbf{j})$ were synthesized and evaluated for RT inhibition activity. Compound $\mathbf{5 a}$ is a bioisoster of virtual hit $\mathbf{3 a}$, but in term of RT inhibition potential, it showed better activity $\left(\mathrm{IC}_{50}=5.92 \mu \mathrm{M}\right)$ than 3a. Further, replacement of para fluoro with hydrogen significantly reduced its activity $(27.26 \mu \mathrm{M})$ while substitution with 2-methoxy (5c) markedly increased the potency $(0.27 \mu \mathrm{M})$, moreover compound $\mathbf{5} \mathbf{c}$ was found to be the most potent among the all tested compounds. In contemporary to this, methoxy at meta position (5d) drastically reduced the activity. Among halogen substituted compounds, chloro at ortho position (5e) favored the RT inhibition activity $(0.76 \mu \mathrm{M})$ while, chloro as well as bromo at meta position (5f and $\mathbf{5} \mathbf{~ g}$ ) was found unfavorable. Compounds with stronger electron withdrawing nitro group at meta position (5h) and compounds having disubstitution with methoxy and chloro (5i and $\mathbf{5 j}$ ) also showed weak activity (see Table 2).

Overall, SAR studies revealed that halogens like bromo and chloro at 5th position of oxindole ring is crucial for RT inhibition activity, further, methoxy or chloro groups at ortho position of phenyl ring significantly favored their RT inhibition activity (Fig. 2).

\subsubsection{Evaluation of anti-HIV-1 activity and cytotoxicity}

All the synthesized compounds $\mathbf{3} \mathbf{a}-\mathbf{-} \mathbf{j}$ were evaluated for anti-HIV-1 activity against wild strain HIV-1 $1_{\text {IIIB }}$ in T lymphocyte cells by syncytia formation assay. The assay is based upon the cytopathic effect (CPE) of HIV-1 and measured the viability of HIV-1 infected T lymphocyte cells [38]. The cytotoxicity of the synthesized compounds on $\mathrm{T}$ cell lines was also assessed by MTT colorimetric assay method [39].

Among the compounds having bromo substitution at oxindole ring (3a-f), virtual hit 3a and compound 3f showed weak potency while four compounds (3b, 3c, 3d and 3e) showed superior potency with $\mathrm{EC}_{50}<11 \mu \mathrm{M}$. It is worthy to note that all four compounds (3b, 3c, 3d and 3e) also showed low micromolar potency against HIV-1 RT. Moreover, compound 3d exhibited sub-micromolar potency against HIV-1 $\left(\mathrm{EC}_{50}=0.19 \mu \mathrm{M}\right)$ as well as HIV-1 RT $\left(\mathrm{IC}_{50}=0.82 \mu \mathrm{M}\right)$ with selectivity index $>2105$. Among the compounds $4 a-f$, none of the compounds showed superior activity against HIV-1 RT, in similar pattern all the compounds showed weak or least activity against HIV-1 also. Compounds bearing 5-chloro at oxindole ring (5a-5j), displayed weak to potent activity against HIV-1. Three compounds $\mathbf{5 b}, \mathbf{5 c}$ and $\mathbf{5 e}$ displayed low micromolar potency, particularly compound $\mathbf{5 c}$ having methoxy substitution at ortho position exhibited nano molar potency $(0.090 \mu \mathrm{M})$ against HIV-1 with selectivity index $>4444$. Further, compound $\mathbf{5 f}$ having meta chloro substitution exhibited moderate antiHIV-1 activity ( $14.51 \mu \mathrm{M})$, while rest of the compounds (5a, $\mathbf{5 d}, \mathbf{5 g}, \mathbf{5 h}$, $\mathbf{5 i}$ and $\mathbf{5 j}$ ) showed weak to least activity. Overall, with few exceptions, most of the compounds showed good to excellent co-relation between RT inhibition and anti-HIV-1 activity (see Table 2). 
Table 2

Results of HIV-1 RT inhibition, anti-HIV-1 and cytotoxicity evaluation.

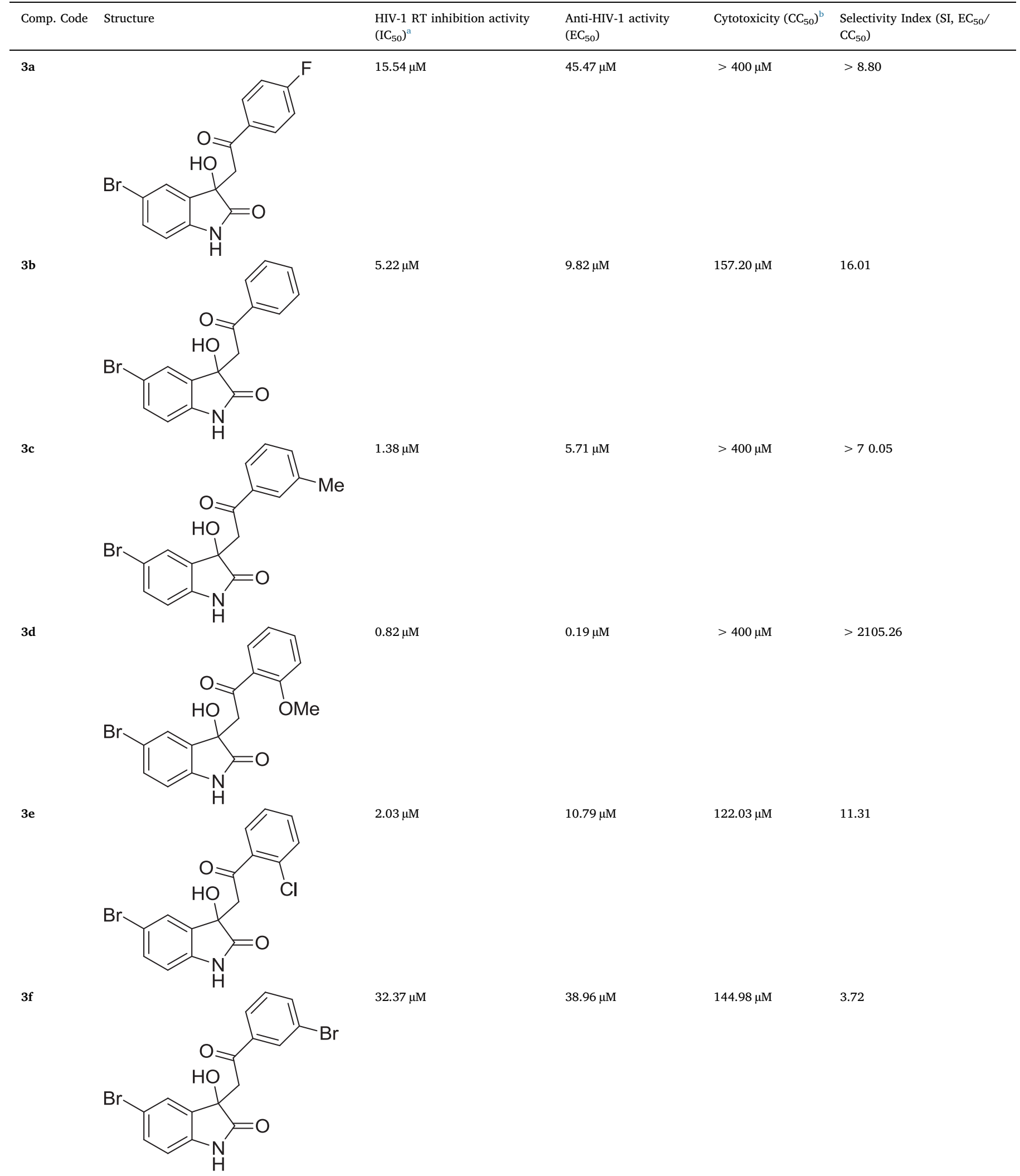




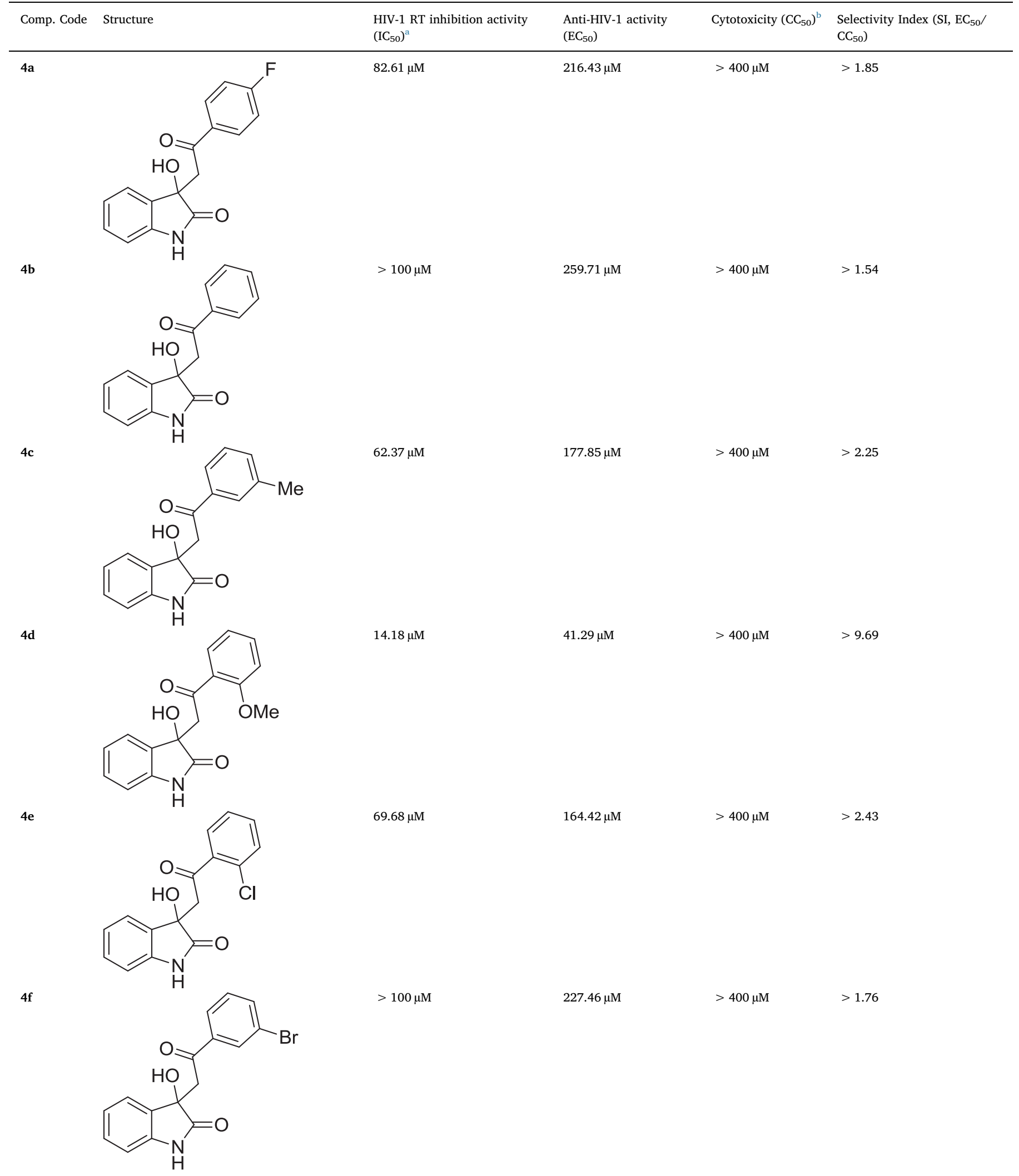


Table 2 (continued)

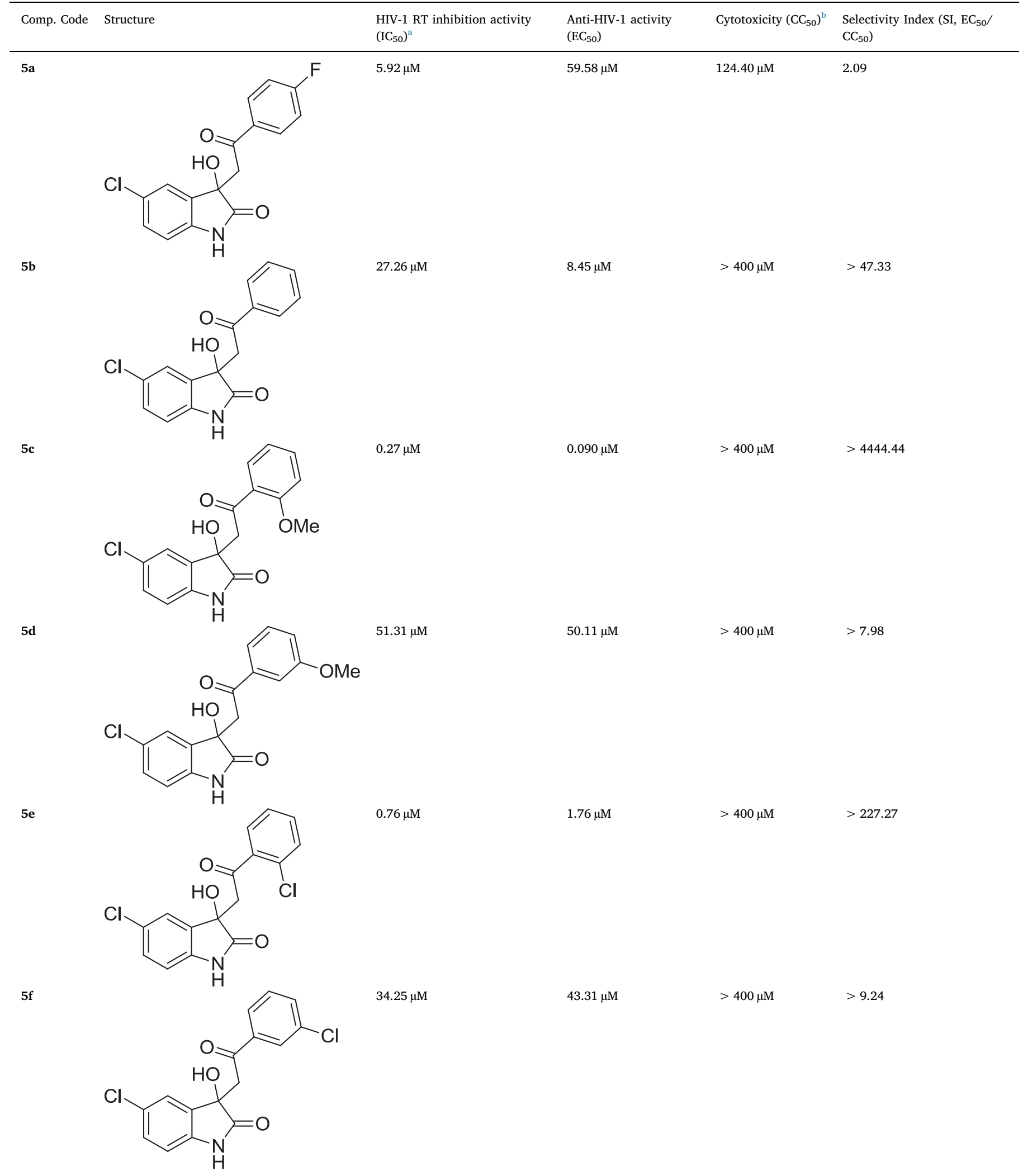


Table 2 (continued)

\begin{tabular}{|c|c|c|c|c|c|}
\hline Comp. Code & Structure & $\begin{array}{l}\text { HIV-1 RT inhibition activity } \\
\left(\mathrm{IC}_{50}\right)^{\mathrm{a}}\end{array}$ & $\begin{array}{l}\text { Anti-HIV-1 activity } \\
\left(\mathrm{EC}_{50}\right)\end{array}$ & Cytotoxicity $\left(\mathrm{CC}_{50}\right)^{\mathrm{b}}$ & $\begin{array}{l}\text { Selectivity Index (SI, EC } 50 \text {. } \\
\mathrm{CC}_{50} \text { ) }\end{array}$ \\
\hline $5 g$ & & $62.14 \mu \mathrm{M}$ & $25.87 \mu \mathrm{M}$ & $146.69 \mu \mathrm{M}$ & 5.67 \\
\hline $5 \mathrm{~h}$ & & $58.51 \mu \mathrm{M}$ & $37.84 \mu \mathrm{M}$ & $121.10 \mu \mathrm{M}$ & 3.20 \\
\hline $5 i$ & & $73.08 \mu \mathrm{M}$ & $61.91 \mu \mathrm{M}$ & $>400 \mu \mathrm{M}$ & $>6.46$ \\
\hline $5 j$ & & $68.86 \mu \mathrm{M}$ & $28.47 \mu \mathrm{M}$ & $118.94 \mu \mathrm{M}$ & 4.18 \\
\hline Efavirenz & & $0.057 \mu \mathrm{M}$ & & & \\
\hline Zidovudine & & & $0.0071 \mu \mathrm{M}$ & $5201.13 \mu \mathrm{M}$ & 732553.53 \\
\hline Lamivudine & & & $0.1690 \mu \mathrm{M}$ & $>1000 \mu \mathrm{M}$ & $>5917.16$ \\
\hline
\end{tabular}

${ }^{\text {a }}$ Value is average of at least two independent experiment, relative standard deviation (RSD) was found within $\pm 15 \%$.

b The symbol ' $>$ ' indicated the compound still non-cytotoxic at the highest concentration was tested.

Anti-HIV-1 activity studies of compounds ( $3 b, 3 c, 3 d, 3 e, 5 b, 5 c, 5 c$ levo, $5 \mathbf{c}$ dextro and $5 \mathrm{e}$ ) against the mutant HIV-1 $1_{\mathrm{K} 103 \mathrm{~N}}$ strain, revealed that all compounds exhibited weak activity. Although, compounds 3d and $5 c$ displayed comparatively better activity $\left(\mathrm{EC}_{50}=74.70\right.$ and $75.33 \mu \mathrm{M}$ ) compared to rest of the compounds (Table 3). Particularly, the dextro enantiomer of compound $\mathbf{5 c}$ exhibited better potency $\left(\mathrm{EC}_{50}=54.30 \mu \mathrm{M}\right) \quad$ compared to its levo enantiomer $\left(\mathrm{EC}_{50}=147.18 \mu \mathrm{M}\right)$ against the HIV-1 $1_{\mathrm{K} 103 \mathrm{~N}}$ strain.

\subsection{Docking studies}

In order to explore the putative binding pattern of the best active compound $\mathbf{5 c}$ inside NNIBP of HIV-1 RT, docking studies were performed. Further, reference drug efavirenz was also made to dock under similar conditions. The docked view of best scoring pose of compound 5c (Fig. 3) was found to be quite similar to binding mode of reference drug efavirenz, for example, cyclopropyl moiety of efavirenz showed prominent hydrophobic interactions with residues like Trp-229, Tyr188, Tyr-181 and Leu-237 (Fig. S1, supplementary information). In similar fashion, 2-methoxyphenyl moiety of compound $\mathbf{5 c}$ showed similar prominent interactions with above mentioned residues and also with residue Phe-227 additionally [Fig. 3]. Furthermore, functionalities like $-\mathrm{C}=\mathrm{O}$ and $-\mathrm{NH}$ of oxazinone ring in efavirenz showed hydrogen bonding interaction with Lys-101, in the same way $-\mathrm{NH}$ of oxindole ring in compound $\mathbf{5 c}$ also exhibited similar interaction with Lys-101. Further, chlorophenyl entity of compound $\mathbf{5 c}$ showed hydrophobic interactions with residues like Val-106 and Tyr-318, corresponding to this, phenyl ring of efavirenz showed similar interaction with both residues. Overall, compound $\mathbf{5 c}$ shared pharmacophoric similarity with efavirenz and also exhibited similar binding pattern with HIV-1 RT that may be responsible for its firm binding with HIV-1 RT and subsequently for potent RT inhibition and anti-HIV-1 activity during the in vitro assay. 


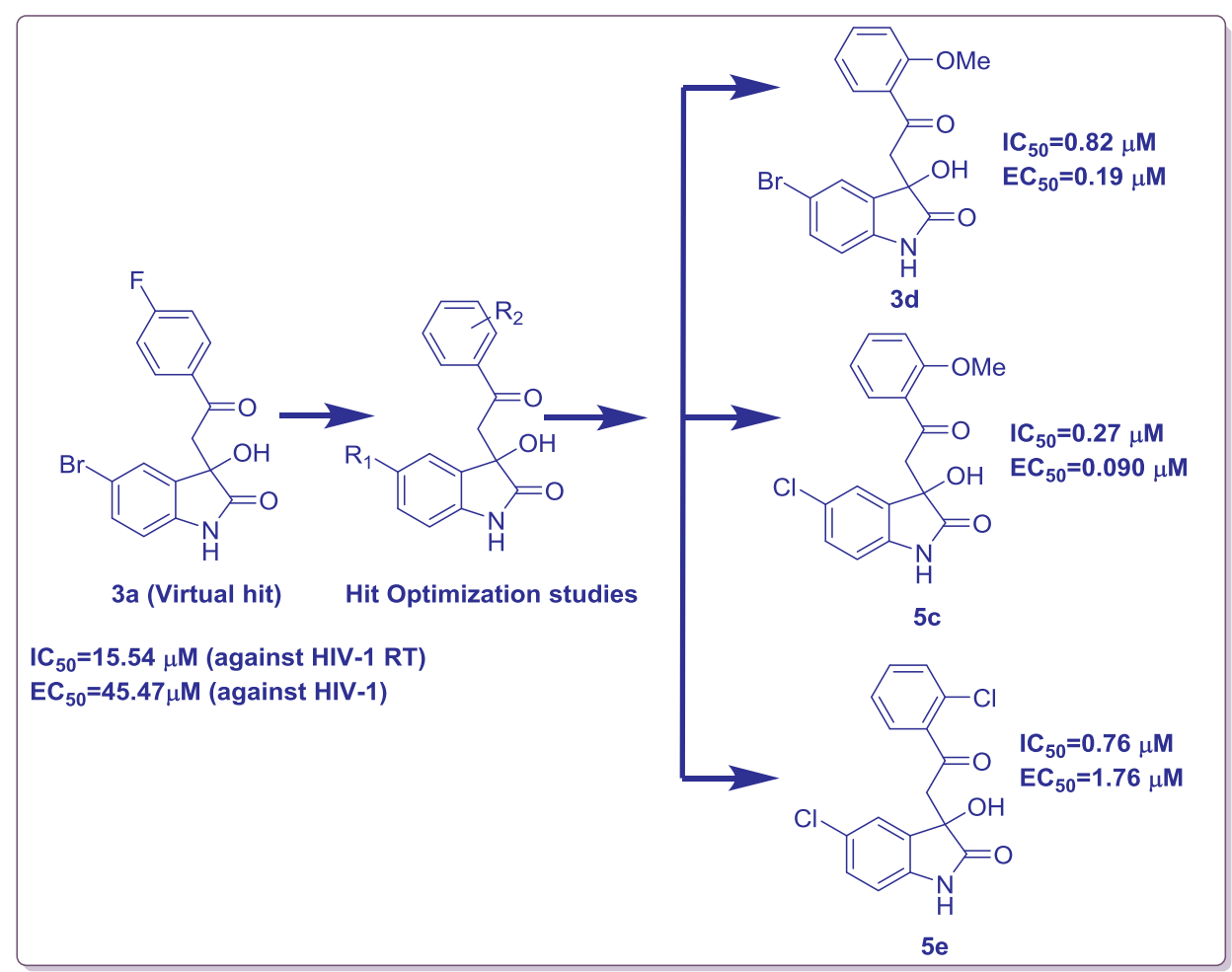

Fig. 2. Hit optimization studies from virtual hit 3a.

Table 3

Results of mutant anti-HIV-1 $1_{\mathrm{K} 103 \mathrm{~N}}$ strain of selected compounds.

\begin{tabular}{|c|c|c|c|}
\hline Number & Experiment & Method & $\mathrm{EC}_{50}(\mu \mathrm{M})^{\mathrm{a}}$ \\
\hline $3 \mathbf{b}$ & Inhibition of HIV-1 p24 antigen production & ELISA & 131.98 \\
\hline 3c & Inhibition of HIV-1 p24 antigen production & ELISA & $>200.00$ \\
\hline 3d & Inhibition of HIV-1 $\mathrm{p} 24$ antigen production & ELISA & 74.70 \\
\hline $3 \mathbf{e}$ & Inhibition of HIV-1 $\mathrm{p} 24$ antigen production & ELISA & 184.46 \\
\hline $5 \mathbf{b}$ & Inhibition of HIV-1 p24 antigen production & ELISA & 176.55 \\
\hline 5c (racemic) & Inhibition of HIV-1 $\mathrm{p} 24$ antigen production & ELISA & 75.33 \\
\hline 5c (levo) & Inhibition of HIV-1 $\mathrm{p} 24$ antigen production & ELISA & 147.18 \\
\hline 5c (dextro) & Inhibition of HIV-1 $\mathrm{p} 24$ antigen production & ELISA & 54.30 \\
\hline $5 e$ & Inhibition of HIV-1 p24 antigen production & ELISA & 129.33 \\
\hline NVP & Inhibition of HIV-1 p24 antigen production & ELISA & 5.38 \\
\hline
\end{tabular}

${ }^{\text {a }}$ Value is the mean of three independent experiments.

\section{Experimental}

\subsection{Chemistry}

All starting materials and reagents purchased from Sigma or SD fine companies were used as received without further purification. Ethyl acetate and hexane mixture (40:60) was used as mobile phase for thin layer chromatography in order to monitor the progress of reaction. Melting points were uncorrected and determined in open capillary tubes using melting point apparatus, Precision Buchi B530 (Flawil, Switzerland) containing silicon oil. The IR spectra of the synthesized compounds were recorded using FTIR spectrophotometer (Shimadzu IR Prestige 21, Shimadzu, Mumbai, India). ${ }^{1} \mathrm{H}$ and ${ }^{13} \mathrm{C}$ NMR spectra were recorded on Bruker DPX-400 spectrometer (Bruker India Scientific Pvt. Ltd., Mumbai, India) using TMS as an internal standard (chemical shifts in $\delta$ ). Elemental analysis was performed on Vario EL III M/s Elementar $\mathrm{C}, \mathrm{H}, \mathrm{N}$ and $\mathrm{S}$ analyzer (ElementarAnalysensysteme $\mathrm{GmbH}$, Hanau, Germany). ESI-MS were recorded on MICROMASS Quattro-II LCMS system (Waters Corporation, Milford, USA).
3.1.1. General procedure for the synthesis of $3 a-5 j$ compounds using optimized reaction condition (a3)

Selected acetophenones (2a-k, $2 \mathrm{mmol}$ ) was stirred in ethanol $(15 \mathrm{ml})$ containing diethylamine $(2.4 \mathrm{mmol}, 0.32 \mathrm{ml})$ for $20 \mathrm{~min}$ at room temperature, then starting material respective isatins (1a-c, 2 mmol) was added slowly in portions. Further, the reaction mass was stirred at room temperature (5-9h) till completion as per TLC. After completion of reaction, ethanol was evaporated on rotary evaporator to half of its original volume and $15 \mathrm{ml}$ of ice cold water was added to the reaction mixture. Resulting precipitates were filtered using vacuum filtration and twice washed with cold ethanol $(2 \times 10 \mathrm{ml})$, followed by diethyl ether $(10 \mathrm{ml})$ and finally dried in oven at $45^{\circ} \mathrm{C}$ to get desired compounds 3a-5j [31-35]. Synthesized compounds were first characterized using non-spectral techniques like TLC and melting point and then by different spectral techniques like IR, ${ }^{1} \mathrm{H}$ NMR, ${ }^{13} \mathrm{C}$ NMR, ESI-MS and elemental analysis. Spectral data of the synthesized compounds are given in the supplementary part of the manuscript.

\subsubsection{Enantiomer separation of compound $5 c$}

The enantiomers of compound $\mathbf{5 c}$ were separated by preparative 


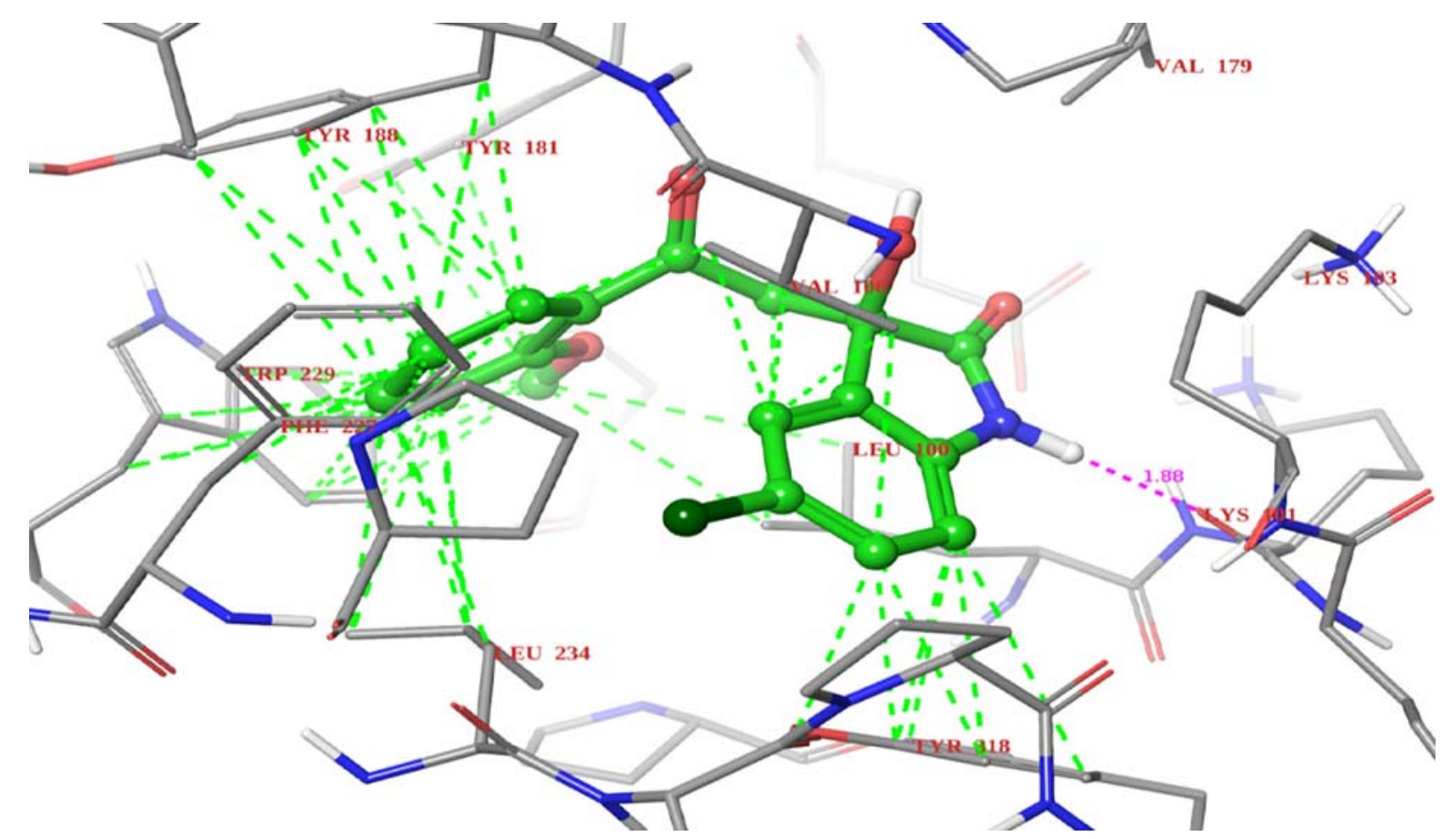

Fig. 3. Docked pose of compound $\mathbf{5 c}$ inside the NNIBP of 3MEE enzyme, showing hydrophobic and hydrogen bonding interactions represented by green and pink dotted lines, respectively.

HPLC using the chiral stationary phase $(S, S)$-Whelk-O1 dimensions $250 \times 10 \mathrm{~mm}$ and mixture of hexane, ethanol dichloromethane as solvent in the ratio of 60: 20: 20 , respectively. Detail of the method used for enantiomer separation is given in the supplementary part of manuscript.

\subsection{In-vitro HIV-1 RT inhibitory assay}

Titled compounds were in vitro evaluated via ELISA based colorimetric assay using RT kit (Roche diagnostics). In the assay marketed drug efavirenz was used as reference positive control. Procedure followed during the assay is briefly described here; the reaction mixture was set with template primer complex, RT enzyme and dNTPs in a lysis buffer with or without inhibitors. The reaction mixture was incubated at $37^{\circ} \mathrm{C}$ for $1 \mathrm{~h}$ and then transferred to streptavidine-coated microtitre plate (MTP). The biotin-labeled dNTPs that were incorporated in the template due to activity of RT, bound to streptavidine. The unbound dNTPs were washed using wash buffer and anti-DIG-POD was added to the MTP. The DIG-labeled dNTPs incorporated in the template were bound to an anti-DIG-POD antibody. The unbound anti-DIG-POD was washed again with washing buffer and the peroxide substrate (ABST) was added to the MTP. A colored reaction product was produced due to the cleavage of the substrate catalyzed by peroxide enzyme. The absorbance of the sample was determined as an optical density (OD) at $405 \mathrm{~nm}$ using a micro titer plate ELISA reader [36,37]. The final value of OD taken was average of duplicate results and $\%$ inhibition of HIV-1 RT was calculated using the below mentioned formula and $\mathrm{IC}_{50}$ was calculated via further double dilutions.

$\%$ Inhibition $=100-\left(\frac{\text { OD at } 405 \mathrm{~nm} \text { with inhibitor }}{\text { OD at } 405 \mathrm{~nm} \text { without inhibitor }} \times 100\right)$

\subsection{Anti-HIV-1 activity and cytotoxicity}

The inhibitory effect of compounds on acute HIV-1 $1_{\text {IIIB }}$ infection was measured by syncytia formation assay. In the presence or absence of various concentrations of samples, exponentially growing C8166 cells were infected with $\mathrm{HIV}-1_{\text {IIIB }}$ at an appropriate multiplicity of infection (MOI) and cultured in 96 -well plates at $37{ }^{\circ} \mathrm{C}$ in $5 \% \mathrm{CO}_{2}$ for 3 days. AZT was used as positive control. At 3 days post-infection, the cytopathic effect (CPE) was measured by counting the number of syncytia (multinucleated giant cell) in each well of 96-well plates under an inverted microscope $(100 \times)$. The inhibitory percentage of syncytia formation was calculated by the percentage of syncytia number in sample treated culture compared to that in infected control culture [38]. Seven compounds (3b, 3c, 3d, 3e, 5b, 5c and 5e) which displayed encouraging potency against wild strains of HIV-1 $\left(\mathrm{EC}_{50} \leq 10.79 \mu \mathrm{M}\right)$ were tested against the mutant $\mathrm{HIV}-1_{\mathrm{K} 103 \mathrm{~N}}$ strain. Moreover, both enantiomers (levo and dextro) of compound $\mathbf{5} \mathbf{c}$ were also tested against the mutant $\mathrm{HIV}-1_{\mathrm{K} 103 \mathrm{~N}}$ strain (detailed method is given supplementary information).

The cellular toxicity of compounds on C8166 cells was also assessed by MTT colorimetric assay, which is based on the reduction of yellow colored MTT by mitochondrial dehydrogenase of metabolically active cells to a blue-purple formazan that can be dissolved in 50\% DMF-15\% SDS. After the formazan was dissolved completely, the plates were analyzed by Bio-TekELx 800 ELISA reader at $570 \mathrm{~nm} / 630 \mathrm{~nm}$ [39].

According to the method described by Reed \& Muench, $50 \%$ cytotoxic concentration $\left(\mathrm{CC}_{50}\right)$ and $50 \%$ effective concentration $\left(\mathrm{EC}_{50}\right)$ was determined from dose-response curve. Selectivity index (SI) of antiHIV-1 activity is $\mathrm{CC}_{50} / \mathrm{EC}_{50}$.

\subsection{Docking studies}

Docking studies of the best active compound $\mathbf{5 c}$ and reference drug efavirenz were performed against wild HIV-1 RT using Glide 5.9 in extra precision mode, running on maestro version 9.4 [40]. Enzyme in complex with co-crystallized ligand (rilpivirine) was retrieved from Protein Data Bank (PDB ID: 3MEE) and prepared using protein preparation wizard of Schrödinger suite [41]. Protein was pre-processed separately by deleting the substrate co-factor as well as the crystallographically observed water molecules (water without $\mathrm{H}$ bonds), followed by optimization of hydrogen bonds. After assigning charge and protonation state, finally energy was minimized with Root Mean Square 
Deviation (RMSD) value of $0.30 \AA$ using Optimized Potentials for Liquid Simulations-2005 (OPLS-2005) force field [42]. Finally, energy minimized protein and co-crystallized ligand was employed to build energy grids within a cubic box around the centroid of the X-ray ligand pose. The structures of the compound $\mathbf{5 c}$, efavirenz and rilpivirine were drawn using ChemSketch and converted to 3D structure with the help of 3D optimization tool. By using LigPrep 2.6 module, the drawn ligands were geometry optimized; partial atomic charges were computed using OPLS-2005 force field [43]. Finally, 32 poses were included with different tautomeric and steric features for docking studies. Finally, prepared ligands were docked with prepared protein using Glide 5.9 module, in extra precision mode (XP). The best docked pose (with lowest Glide score value) obtained from Glide was analyzed. The value of Root-Mean-Square Deviation (RMSD) between the X-ray binding pose in protein-ligand complex and re-docked pose was found to be 0.62 , which demonstrated the accuracy and reliability of the docking protocol (Fig. S2, supplementary sheet).

\section{Conclusion}

In conclusion, series of twenty-two compounds was synthesized based on the pharmacophoric features of virtual screened hit and subsequently studied for HIV-1 RT inhibition, anti-HIV-1 activity and cytotoxicity. Among the all compounds, seven compounds (3b, 3c, 3d, 3e, 5a, 5c and 5e) inhibited the activity of HIV-1 RT with $\mathrm{IC}_{50}<6 \mu \mathrm{M}$, in which $3 d, 5 \mathbf{c}$ and 5 e displayed sub-micromolar potency with $\mathrm{IC}_{50}$ of $0.27,0.76$ and $0.82 \mu \mathrm{M}$, respectively. SAR studies revealed that halogens like bromo or chloro at 5th position of oxindole ring is crucial for HIV-1 RT inhibition activity and methoxy or chloro groups at ortho position of phenyl ring also significantly favored RT inhibition activity. Six compounds (3b, 3c, 3d, 5b, 5c and 5e) displayed encouraging antiHIV-1 activity with $\mathrm{EC}_{50}<10 \mu \mathrm{M}$, particularly, three compounds 3d, $\mathbf{5 c}$ and $\mathbf{5 e}$ were found to be potently active against HIV-1 RT as well as HIV-1 in low to sub-micromolar range with good to excellent safety index. Majority of the compounds showed good to excellent co-relation between HIV-1 RT inhibition activity and anti-HIV-1 activity. Current study afforded compound $\mathbf{5 c}$ which possessed sub-micromolar $(0.27 \mu \mathrm{M})$ and nanomolar $(90 \mathrm{nM})$ potency against HIV-1 RT and HIV-1, respectively with excellent safety index ( $>4444$ ). Compounds $3 \mathbf{b}, 3 \mathbf{3}$, $3 d, 3 e, 5 b, 5 c, 5 c_{\text {levo }}, 5 c_{\text {dextro }}$ and $5 e$ were found be weakly active against mutant HIV-1 $1_{\mathrm{K} 103 \mathrm{~N}}$ strain. Although, the dextro enantiomer of compound $5 \mathrm{c}$ showed better potency $\left(\mathrm{EC}_{50}=54.30 \mu \mathrm{M}\right)$ compared to its levo enantiomer $\left(\mathrm{EC}_{50}=147.18 \mu \mathrm{M}\right)$. Compound $5 \mathrm{c}$ shared pharmacophoric similarity as well as binding pattern with efavirenz that may be accounted for its firm binding with wild HIV-1 RT and subsequently for potent RT inhibitory activity. Overall, study can be helpful for de novo designing of HIV-1 RT inhibitor or further lead optimization study to find more potent and safe anti-HIV-1 agents.

\section{Acknowledgments}

Authors gratefully acknowledge BITS-Pilani for providing the necessary facilities to do this work. This work was carried out under a grant from Science and Engineering Research Board of Department of Science and Technology, New Delhi. (Ref. No: SR/FT/LS-58/2011). This work was supported in part by grants from the Key Scientific and Technological Program of China (2014ZX10005-002-006) and of Yunnan Province (2015FB182), and the Chinese Academy of Sciences (CASIMM0320163020).
[1] R.A. Spence, W.M. Kati, K.S. Anderson, K.A. Johnson, Mechanism of inhibition of HIV-1 reverse transcriptase by non-nucleoside inhibitors, Science 267 (1995) 988-993.

[2] N. Sluis-Cremer, G. Tachedjian, Mechanisms of inhibition of HIV replication by nonnucleoside reverse transcriptase inhibitors, Virus Res. 134 (2008) 147-156.

[3] S.G. Sarafianos, B. Marchand, K. Das, D.M. Himmel, M.A. Parniak, S.H. Hughes, E. Arnold, Structure and function of HIV-1 reverse transcriptase: molecular mechanisms of polymerization and inhibition, J. Mol. Biol. 385 (2009) 693-713.

[4] J.R. Brechtl, W. Breitbart, M. Galietta, S. Krivo, B. Rosenfeld, The use of Highly Active Anti Retroviral Therapy (HAART) in patients with advanced HIV infection: impact on medical, palliative care and quality of life outcomes, J. Pain Symptom Manag. 21 (2001) 41-51.

[5] I. Usach, V. Melis, J.E. Peris, Non-nucleoside reverse transcriptase inhibitors: a review on pharmacokinetics, pharmacodynamics, safety and tolerability, J. Int. AIDS Soc. 16 (2013) 1-14.

[6] S. Chander, P. Ashok, Y.T. Zheng, P. Wang, K.S. Raja, A. Taneja, S. Murugesan, Design, synthesis and in-vitro evaluation of novel tetrahydroquinolinecarbamates as HIV-1 RT inhibitor and their antifungal activity, Bioorg. Chem. 64 (2016) 66-73.

[7] Z. Li, B. Terry, W. Olds, T. Protack, C. Deminie, B. Minassian, B. Nowicka-Sans, Y. Sun, I. Dicker, C. Hwang, M. Lataillade, G.J. Hanna, M. Krystal, In vitro crossresistance profile of nucleoside reverse transcriptase inhibitor (NRTI) BMS-986001 against known NRTI resistance mutations, Antimicrob Agents Chemother. 57 (2013) 5500-5508.

[8] A.E. Basson, S.Y. Rhee, C.M. Parry, Z. El-Khatib, S. Charalambous, T. De Oliveira, D. Pillay, C. Hoffmann, D. Katzenstein, R.W. Shafer, L. Morris, Impact of drug resistance-associated amino acid changes in HIV-1 subtype C on susceptibility to newer non-nucleoside reverse transcriptase inhibitors, Antimicrob Agents Chemother. 59 (2015) 960-971.

[9] K. Singh, B. Marchand, K.A. Kirby, E. Michailidis, S.G. Sarafianos, Structural aspects of drug resistance and inhibition of HIV-1 reverse transcriptase, Viruses 2 (2010) 606-638.

[10] N. Sluis-Cremer, M.A. Wainberg, R.F. Schinazi, Resistance to reverse transcriptase inhibitors used in the treatment and prevention of HIV-1 infection, Future Microbiol. 10 (2015) 1773-1782.

[11] K. Das, J.D. Bauman, A.D. Clark Jr, Y.V. Frenkel, P.J. Lewi, A.J. Shatkin, S.H. Hughes, E. Arnold, High-resolution structures of HIV-1 reverse transcriptase/ TMC278 complexes: strategic flexibility explains potency against resistance mutations, Proc. Natl. Acad. Sci. USA 105 (2008) 1466-1471.

[12] D.B. Kitchen, H. Decornez, J.R. Furr, J. Bajorath, Docking and scoring in virtual screening for drug discovery: methods and applications, Nat. Rev. Drug Discov. 3 (2004) 935-949.

[13] E. Lionta, G. Spyrou, D.K. Vassilatis, Z. Cournia, Structure-based virtual screening for drug discovery: principles, applications and recent advances, Curr. Top Med. Chem. 14 (2014) 1923-1938.

[14] B.O. Villoutreix, R. Eudes, M.A. Miteva, Structure-based virtual ligand screening: recent success stories, Comb. Chem. High Throughput Screen 12 (2009) 1000-1016.

[15] Chander S, Pandey RK, Penta A, Choudhary BS, Sharma M, Malik R, Prajapati VK, Murugesan S. Molecular docking and molecular dynamics simulation based approach to explore the dual inhibitor against HIV-1 reverse transcriptase and Integrase. Comb Chem High Throughput Screen. 2017, 20 (article in press), doi: 10. 2174/1386207320666170615104703.

[16] C. Liao, M.C. Nicklaus, Computer tools in the discovery of HIV-I integrase inhibitors, Future Med. Chem. 2 (2010) 1123-1140.

[17] G. Hu, X. Li, X. Zhang, Y. Li, L. Ma, L.M. Yang, G. Liu, W. Li, J. Huang, X. Shen, L. Hu, Y.T. Zheng, Y. Tang, Discovery of inhibitors to block interactions of HIV-1 integrase with human LEDGF/p75 via structure-based virtual screening and bioassays, J. Med. Chem. 55 (2012) 10108-10117.

[18] S. Chander, A. Penta, S. Murugesan, Structure-based virtual screening and docking studies for the identification of novel inhibitors against wild and drug resistance strains of HIV-1 RT, Med. Chem. Res. 24 (2015) 1869-1883.

[19] S. Chander, C.R. Tang, H. Mohammed Al-Maqtari, J. Jamalis, A. Penta, T.B. Hadda, H.M. Sirat, Y.T. Zheng, S. Murugesan, Synthesis and study of anti-HIV-1 RT activity of 5-benzoyl-4-methyl-1,3,4,5-tetrahydro- $2 \mathrm{H}$-1,5-benzodiazepin-2-one derivatives, Bioorg. Chem. 72 (2017) 74-79.

[20] D. Li, P. Zhan, E. De Clercq, X. Liu, Transcriptase inhibitors: lessons from the development of seven representative paradigms, J. Med. Chem. 55 (2012) 3595-3613.

[21] S. Chander, P. Wang, P. Ashok, L.M. Yang, Y.T. Zheng, M. Sankaranarayanan, Design, synthesis and anti-HIV-1 RT evaluation of 2-(benzyl(4-chlorophenyl) amino)-1-(piperazin-1-yl)ethanone derivatives, Bioorg. Med. Chem. Lett. 27 (2017) 61-65.

[22] P. Zhan, X. Chen, D. Li, Z. Fang, E. De Clercq, X. Liu, HIV-1 NNRTIs: structural diversity, pharmacophore similarity, and implications for drug design, Med. Res. Rev. 33 (Suppl 1) (2013) E1-72. 
[23] S. Chander, P. Ashok, A. Singh, S. Murugesan, De-novo design, synthesis and evaluation of novel 6,7-dimethoxy-1,2,3,4-tetrahydroisoquinoline derivatives as HIV-1 reverse transcriptase inhibitors, Chem. Cent. J. 9 (2015) 33, http://dx.doi.org/10. 1186/s13065-015-0111-6.

[24] T.M. Williams, T.M. Ciccarone, S.C. MacTough, C.S. Rooney, S.K. Balani, J.H. Condra, E.A. Emini, M.E. Goldman, W.J. Greenlee, L.R. Kauffman, et al., 5chloro-3-(phenylsulfonyl)indole-2 carboxamide: a novel, non-nucleoside inhibitor of HIV-1 reverse transcriptase, J. Med. Chem. 36 (1993) 1291-1294.

[25] G. La Regina, A. Coluccia, A. Brancale, F. Piscitelli, V. Gatti, G. Maga, A. Samuele, C. Pannecouque, D. Schols, J. Balzarini, E. Novellino, R. Silvestri, Indolyl arylsulfones as HIV-1 non-nucleoside reverse transcriptase inhibitors: new cyclic substituents at indole-2-carboxamide, J. Med. Chem. 54 (2011) 1587-1598.

[26] C. Dousson, F.R. Alexandre, A. Amador, S. Bonaric, S. Bot, C. Caillet, T. Convard, D. da Costa, et al., Discovery of the aryl-phospho-indole IDX899, a highly potent anti-HIV Non-nucleoside reverse transcriptase inhibitor, J. Med. Chem. 59 (2016) 1891-1898.

[27] Storer R, Alexandre F-R, Dousson C, et al. inventors; Idenix Pharmaceuticals, Inc. assignee. Enatiomerically pure phosphoindoles as HIV inhibitors. United States patent. 2008, WO2008/042240.

[28] M. Hassam, A.E. Basson, D.C. Liotta, L. Morris, W.A. Van Otterlo, S.C. Pelly, Novel cyclopropyl-indole derivatives as HIV non-nucleoside reverse transcriptase inhibitors, ACS Med. Chem. Lett. 3 (2012) 470-475.

[29] O.S. Pedersen, E.B. Pedersen, Non-nucleoside reverse transcriptase inhibitors: the NNRTI boom, Antivir Chem. Chemother. 10 (1999) 285-314.

[30] M.L. Barreca, A. Rao, L. De Luca, N. Iraci, A.M. Monforte, G. Maga, E. De Clerce, C. Pannecouque, J. Balzarini, A. Chimirri, Discovery of novel benzimidazolones as potent non-nucleoside reverse transcriptase inhibitors active against wild-type and mutant HIV-1 strains, Bioorg. Med. Chem. Lett. 17 (2007) 1956-1960.

[31] A.K. Gupta, S. Kalpana, J.K. Malik, Synthesis and in vitro antioxidant activity of new 3-substituted-2-oxindole derivatives, Indian J. Pharm. Sci. 74 (2012) 481-486.

[32] M. Bai, Y. You, Y.Z. Chen, G.Y. Xiang, X.Y. Xu, X.M. Zhang, W.C. Yuan, An unprecedented protocol for the synthesis of 3-hydroxy-3-phenacyloxindole derivatives with indolin-2-ones and $\alpha$-substituted ketones, Org. Biomol. Chem. 14 (2016)
1395-1401.

[33] H.M. Meshram, P.B. Thakur, M.B. Bejiam, V.M.D.M.F. Bangade, mediated Henry reaction of isatins: an efficient synthesis of 3-hydroxy-2-oxindole, Green Chem. Lett. Rev. 6 (2013) 19-43.

[34] N. Kumar, J. Kaur, A. Kumar, N. Islam, S.S. Chimni, Catalyst-free synthesis of 3-aryl3-hydroxy-2-oxindole derivatives by using water as the solvent: experimental and DFT studies, Asian J. Org. Chem. 5 (2016) 1334-1344.

[35] P.N. Tosso, Y. Kong, L. Scher, R. Cummins, J. Schneider, S. Rahim, K.T. Holman, J. Toretsky, K. Wang, A. Üren, M.L. Brown, Synthesis and structure-activity relationship studies of small molecule disruptors of EWS-FLI1 interactions in Ewing's sarcoma, J. Med. Chem. 57 (2014) 10290-10303.

[36] J. Eberle, C.W. Knopf, Non-isotopic assays of viral polymerases and related proteins, Methods Enzymol. 275 (1996) 257-276.

[37] S. Chander, P. Wang, P. Ashok, L.M. Yang, Y.T. Zheng, S. Murugesan, Rational design, synthesis, anti-HIV-1 RT and antimicrobial activity of novel 3-(6-methoxy3,4-dihydroquinolin-1(2H)-yl)-1-(piperazin-1-yl)propan-1-one derivatives, Bioorg. Chem. 67 (2016) 75-83.

[38] J.H. Wang, H.L. Nie, S.C. Tam, H. Huang, Y.T. Zheng, Anti-HIV-1 property of trichosanthin correlates with its ribosome inactivating activity, FEBS Lett. 531 (2002) 295-298.

[39] Y.T. Zheng, K. Ben, S.W. Jin, Alpha-momorcharin inhibits HIV-1 replication in acutely but not chronically infected T lymphoid cells, Acta Pharmacol. Sin 20 (1999) 239-243.

[40] Glide, Schrödinger, LLC, New York, 2013, version 5.9.

41] E.B. Lansdon, K.M. Brendza, M. Hung, R. Wang, S. Mukund, D. Jin, G. Birkus, N. Kutty, X. Liu, Crystal structures of HIV-1 reverse transcriptase with etravirine (TMC125) and rilpivirine (TMC278): implications for drug design, J. Med. Chem. 53 (2010) 4295-4299.

[42] W.L. Jorgensen, D.S. Maxwell, R.J. Tirado, Development and testing of the OPLS allatom force field on conformational energetics and properties of organic liquids, J. Am. Chem. Soc. 118 (1996) 11225-11236.

[43] Lig-Prep, Schrödinger, LLC, New York, 2013, version 2.6. 